\title{
A study on the Relationship between Relationship Stability, Trust and cooperative performance in supply chain
}

\author{
Jingjing Han \\ School of Management, Tianjin University of Technology, Tianjin 300384, China \\ 13820757926@163.com
}

Keywords: supply chain, Relationship Stability, Trust, cooperative performance.

\begin{abstract}
Based on the theoretical regression, theoretical model of relationships among relationship stability, trust and cooperative performance is proposed and empirically tested using the date from 156 enterprises in supply chain through the structural equation modeling. The results show that relationship stability can be directly related to the cooperative performance, and it can also be indirectly related to the cooperative performance through the trust path.
\end{abstract}

\section{Introduction}

With the changing of the market competition environment, supply chain enterprise is gradually realized that it is hard to meet the requirements of the new environment by adopting the discrete trading mode which depends on the strength of the enterprise itself. The members of the stability relationship have a clear understanding of the role task, and don't need a complex governance structure and supervision system, thus bringing higher efficiency. At present, the relationship between the relationship stability and the cooperative performance has been studied, but most studies are relationship stability of direct effect on cooperative performance and don't considering relationship stability of indirect effect on cooperative performance. Based on this, this paper takes trust as an intermediary to study the effect of relationship stability on cooperative performance, aimed at providing reliable theoretical basis for partnership establishment and maintenance in supply chain and improvement of cooperation performance.

\section{Related Research and hypothesis}

Relationship stability refers to the balance of dynamic friendly cooperative relations among the parties to the cooperation. Y. Liu et al. ${ }^{[1]}$ proved that relational stability includes relationship length and relationship attitude. Relationship length refers to the duration of the relationship among supply chain enterprises. Relationship attitude is the member enterprise's view on maintaining the relationship among members, and it depends on the quality of relationship. This paper adopts Y. Liu's point of view, from two aspects of relationship length and relational attitude to measure relationship stability.

Trust creates a better environment for the company, and provides power for cooperation and reducing uncertainty. Referring to X.L Zhang's research on the stage of development of trust, trust is divided into Computational trust and relational trust [2]. Computational trust is in the rational trust stage, and trust's expected profit is greater than or equal to the expected losses, and the feature of the trust can be calculated. Relational trust is in the stage of perceptual trust, and both sides are predictable.

According to social exchange theory, cooperative enterprises through long-term adjustment, to end dissatisfied cooperation, the surviving enterprises must have a high degree of matching [3]. It was also because the two sides in a long-term relationship accumulated plenty of experience of cooperation, which is to become the foundation of trust between enterprises. Based on this, we can assume:

H1: Relationship length is positively related to computational trust in supply chain.

$\mathrm{H} 2$ : Relationship length is positively related to relational trust in supply chain. 
Shared values as a source of trust, it requires that trading partners through the communication of the motivation and objectives of the transaction have a common understanding. Shared values that consistency views is the content of relationship attitude. Based on this, we can assume:

H3: Relationship attitude is positively related to computational trust in supply chain.

H4: Relationship attitude is positively related to relational trust in supply chain.

Building trust relationship between supply chain enterprises not only can reduce the transaction cost, but also can improve the success rate of cooperation and profitability. Based on the organizational climate of mutual trust, cooperation effectiveness will be higher. Based on this, we can assume:

H5: Computational trust is positively related to cooperative performance in supply chain.

H6: Relational trust is positively related to cooperative performance in supply chain.

In the cooperation of supply chain enterprises, the establishment of a stable and appropriate partnership is an important guarantee for the improvement of supply chain alliance performance, and is the foundation of the effective operation of supply chain alliance. G. V. Krogh et al. [4] Pointed that relationship stability is good for improving alliance performance, because it provides opportunities for learning, acquiring knowledge, sharing and innovating. Sheng bu-bing have proved that relationship stability in Supply chain has a positive influence on alliance performance [5] .Based on this, we can assume:

H5: Relationship length is positively related to cooperative performance in supply chain.

H6: Relationship attitude is positively related to cooperative performance in supply chain.

\section{Theoretical Model}

Based on the analysis of the above, we put forward the theoretical model of this paper, as shown in Figure 1 (the sign in parentheses indicates the direction of the influence, namely"+").

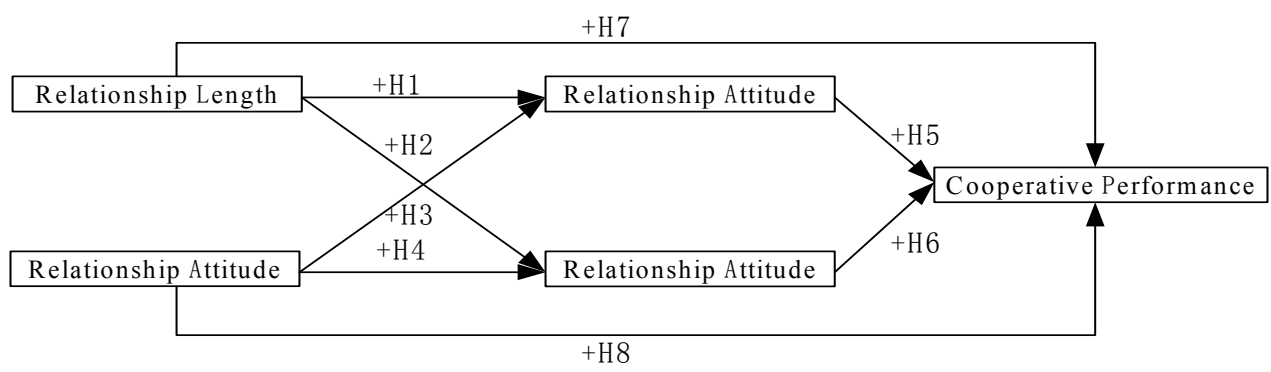

Figure 1 Theoretical model

\section{Research design}

\section{Data collection.}

This study adopts questionnaire survey method to collect samples and questionnaire targeted at the key staff of supply chain member enterprises in the manufacturing industry. This paper uses five level scale to quantify the questions item. The electronic questionnaire and paper questionnaires with a combination of payments, issued a total of 500 questionnaires, after deducting the answer is not complete and some non-manufacturing questionnaire, recycling effective questionnaire 215 , the effective recovery rate was $43 \%$.

\section{Factor analysis.}

In this paper, the reliability and validity of the measurement index were analyzed by Cronbach's $\alpha$ coefficient and factor load values. The results shown in Table 1, that Cronbach's a coefficient of each index greater than 0.7 , factor load of each observation variable greater than 0.5 , which means 
that the scale has good internal consistency and the validity of the selected factors of each variable was satisfactory.

Table 1 Factor analysis

\begin{tabular}{cccccccc}
\hline Variable & Items & $\alpha$ & Load & Variable & Items & $\alpha$ & Load \\
\hline Relationship length & RL1 & -- & -- & & RT13 & 0.732 \\
Relationship Attitude & RA2 & 0.887 & 0.705 & & RT14 & 0.741 \\
& RA3 & & 0.732 & & RT15 & 0.693 \\
& RA4 & & 0.693 & & RT16 & 0.764 \\
Computational Trust & CT5 & 0.854 & 0.658 & & RT17 & 0.640 \\
& CT6 & & 0.647 & & RT18 & 0.605 \\
& CT7 & & 0.770 & Cooperative & CP19 & 0.869 & 0.671 \\
& CT8 & & 0.736 & Performance & CP20 & 0.738 \\
& CT9 & & 0.629 & & CP21 & 0.719 \\
Relational Trust & CT10 & & 0.687 & & CP22 & 0.664 \\
& RT11 & 0.819 & 0.533 & & CP23 & 0.757 \\
& RT12 & & 0.804 & & CP24 & 0.628 \\
\hline
\end{tabular}

Correlation analysis.

Table 2 shows the correlation of the variables, and we can see that the correlation between the variables are significant.

Table 2 Correlation Analysis

\begin{tabular}{cccccc}
\hline & 1 & 2 & 3 & 4 & 5 \\
\hline Relationship Length(RL) & 1.000 & & & & \\
Relationship Attitude(RA) & $0.596^{* *}$ & 1.000 & & & \\
Computational Trust(CT) & $0.583^{* *}$ & $0.647^{* *}$ & 1.000 & & \\
Relational Trust(RT) & $0.404^{* *}$ & $0.328^{* *}$ & $0.399^{* *}$ & 1.000 & \\
Cooperative Performance(CP) & $0.684^{* *}$ & $0.480^{* *}$ & $0.503^{* *}$ & $0.560^{* *}$ & 1.000 \\
\hline Average & 3.541 & 3.456 & 3.701 & 3.466 & 3.553 \\
\hline Standard deviation & 0.575 & 0.639 & 0.698 & 0.626 & 0.641 \\
\hline
\end{tabular}

Note: $* *$ indicates $\mathrm{P}<0.01$

\section{Hypothesis test results}

This paper uses structural equation modeling analysis software Amos17.0 to verify. $x 2 / \mathrm{df}=1.359$ between $1 \sim 3, \mathrm{P}=0.057(>0.05), \mathrm{GFI}=0.934, \mathrm{AGFI}=0.931$ all above $0.90, \mathrm{RMSEA}=0.0337$ $(<0.05)$, which indicates absolute fitting level of the model is very good. IFI $=0.991$, TLI $=0.991$, $\mathrm{CFI}=0.991$ all above close to 1 , which indicates a higher fitting degree of the model. Table 3 is the verification result of eight assumptions, the results generally support the concept of this article models, only $\mathrm{H} 7$ failed the test.

Table 4 shows that the relationship between relationship attitude and cooperative performance is greatly influenced by the trust of the enterprise.

Table 3 Hypothesis test results

\begin{tabular}{ccccc}
\hline Hypothesis & Path & Standard path coefficient & P-values & Results \\
\hline H1 & $\mathrm{RL} \rightarrow \mathrm{CT}$ & 0.501 & 0.033 & True \\
$\mathrm{H} 2$ & $\mathrm{RL} \rightarrow \mathrm{RT}$ & 0.475 & 0.000 & True \\
$\mathrm{H} 3$ & $\mathrm{RA} \rightarrow \mathrm{CT}$ & 0.376 & 0.026 & True \\
$\mathrm{H} 4$ & $\mathrm{RA} \rightarrow \mathrm{RT}$ & 0.621 & 0.041 & True \\
$\mathrm{H} 5$ & $\mathrm{CT} \rightarrow \mathrm{CP}$ & 0.509 & 0.000 & True \\
$\mathrm{H} 6$ & $\mathrm{RT} \rightarrow \mathrm{CP}$ & 0.449 & 0.000 & True \\
$\mathrm{H} 7$ & $\mathrm{RL} \rightarrow \mathrm{CP}$ & 0.481 & 0.809 & False \\
$\mathrm{H} 8$ & $\mathrm{RA} \rightarrow \mathrm{CP}$ & 0.107 & 0.000 & True \\
\hline
\end{tabular}


Table 4 Effect of Intermediary

\begin{tabular}{ccccc}
\hline & Path & Each path effect value & Sum of Direct /Indirect Effects & Sum \\
\hline Direct & $\mathrm{RL} \rightarrow \mathrm{CP}$ & -- & -- & \\
Indirect & $\mathrm{RL} \rightarrow \mathrm{CT} \rightarrow \mathrm{CP}$ & $0.501^{*} 0.509=0.255$ & 0.468 & 0.468 \\
& $\mathrm{RL} \rightarrow \mathrm{RT} \rightarrow \mathrm{CP}$ & $0.475^{*} 0.449=0.213$ & & \\
\hline Direct & $\mathrm{RA} \rightarrow \mathrm{CP}$ & 0.107 & 0.107 & 0.470 \\
Indirect & $\mathrm{RA} \rightarrow \mathrm{CT} \rightarrow \mathrm{CP}$ & $0.376^{*} 0.509=0.191$ & & 0.577 \\
& $\mathrm{RA} \rightarrow \mathrm{RT} \rightarrow \mathrm{CP}$ & $0.621^{*} 0.449=0.279$ & & \\
\hline
\end{tabular}

\section{Conclusions}

This study shows that the stability can be directly effect on cooperative performance, but also can indirectly on cooperative performance by the path of trust, and to a greater extent depends on the indirect effect.

The longer the time elapsed between the business relationship, the more computational trust, and increased computational trust allows companies with a more rational attitude to treat cooperation, thus contributing to improve the cooperative performance.

The close relationship between the companies in the long-term cooperation forms a good relationship attitude, reducing the possibility of opportunistic behavior among enterprises and promoting cooperation between enterprises, thus improving performance. Of course, good relations with the attitude of the two sides also indirectly promote cooperative performance by the relational trust. This paper is of great significance for understanding the improvement of the cooperative performance in the stable stage of the relationship.

\section{References}

[1]. Y. Liu, L.Tao, Y. Wang. A Study on the Relationship between Retailers, Supply Relationship Stability, Trust and Relational Risk [J]. Forecasting. Vol. 28 (2009) No. 01, p.36-41.

[2]. X.L Zhang. Study on Knowledge Management Mechanism for Trust-based Supply Chain [J].Innovation. Vol. 09 (2015) No. 01, p.111-114.

[3]. Young-Ybarra C, Wiersema M. Strategic flexibility in information technology alliance: the influence of transaction cost economics and social exchange theory [J]. Organization Science. Vol. 10(1999) No. 04, p.439-460.

[4]. G.V. Krogh, I. Nonaka and M. Aben, Making the most of your company's knowledge: a strategic framework, Long Range Planning. Vol. 34(2001) No. 04, p. 421-439.

[5]. B.B Sheng: Empirical Study on the relationship between supply chain alliance and its effect on the alliance performance (Ph.D., Yangzhou University, China 2009), p. 12. 